FELTRAN, J.C.; LEMOS, L.B.; ARTIOLI, G.M.; BANZATTO, D.A. Esverdeamento em cultivares de batata avaliado pela escala visual e índice spad. Horticultura Brasileira, Brasília, v.22, n.4, p.681-685, out-dez 2004.

\title{
Esverdeamento em cultivares de batata avaliado pela escala visual e índice spad
}

\author{
José Carlos Feltran ${ }^{1}$; Leandro B. Lemos ${ }^{1}$; Gisele Maria Artioli ${ }^{1}$; David Ariovaldo Banzatto ${ }^{2}$
}

${ }^{1}$ UNESP, FCA, Depto. Produção Vegetal, C. Postal 237, 18603-970 Botucatu-SP. E-mail: feltranjc@ @fca.unesp.br; leandrobl@fca.unesp.br; ${ }^{2}$ UNESP, FCAV, Depto. Ciências Exatas, 14884-900 Jaboticabal-SP

\section{RESUMO}

Foi avaliado o esverdeamento em tubérculos de cultivares de batata utilizando dois métodos de determinação (escala visual de notas e índice spad). Utilizou-se o delineamento experimental inteiramente casualizado, com quatro repetições, em esquema fatorial 18 x 5, constituído por cultivares (Agata, Apuã (IAC-5977), Aracy (IAC-2), IAC Aracy Ruiva, Asterix, Bintje, Dali, Clone IAC-6090, Itararé (IAC-5986), Laguna, Remarka, Liseta, Mondial, Novita, Oscar, Picasso, Santana e Solide) e tempo de armazenamento (5; 10; $15 ; 20$ e 25 dias). Todas as cultivares apresentaram desempenho linear e crescente pelo índice spad, com excecão da Bintje, com spad médio de 1,23. Pela escala visual, as cultivares apresentaram desempenho quadrático e linear. A cultivar Bintje é resistente ao esverdeamento determinado pelos dois métodos. O índice spad pode ser utilizado para determinação do esverdeamento do $10^{\circ}$ ao $25^{\circ}$ dia de armazenamento.

Palavras-chave: Solanum tuberosum, tubérculos, distúrbio fisiológico, esverdeamento, métodos.

\begin{abstract}
Greening of potato cultivars evaluated through visual scale and spad index

The occurrence of greening in potato tubers was evaluated through two evaluation methods (visual scale of notes and spad index). The experimental design was a completely randomized, with four replications. Treatments were disposed in the factorial sceme 18x5, constituted of potato cultivars (Agata, Apuã (IAC-5977), Aracy (IAC-2), IAC Aracy Ruiva, Asterix, Bintje, Dali, Clone IAC-6090, Itararé (IAC-5986), Laguna, Remarka, Liseta, Mondial, Novita, Oscar, Picasso, Santana and Solide) and storage time (5; 10; 15; 20 and 25 days). All potato cultivars presented positive linear effects when evaluated through the spad index, except 'Bintje', with average spad index of 1,23 . For the visual scale, quadratic and linear effects were verified. 'Bintje' is resistant to the greening when evaluated by both methods. The spad index can be used for determining of the greening from $10^{\circ}$ to the $25^{\circ}$ day of storage.
\end{abstract}

Keywords: Solanum tuberosum, tubers, physiological disturbs, greening, methods.

\section{(Recebido para publicação em 24 de outubro de 2003 e aceito em 13 de setembro de 2004)}

$\mathrm{O}$ uso de novas cultivares de batata nas regiões produtoras do Brasil está em expansão; porém a falta de conhecimento sobre a suscetibilidade dos tubérculos ao distúrbio fisiológico denominado esverdeamento, pode comprometer a aceitação pelo mercado consumidor e resultar em prejuízos a toda cadeia produtiva da batata.

O tubérculo de batata é um caule modificado com folhas e gemas axilares muito reduzidas, internódios curtos e expansão radial, tendo nos grãos de amido seu componente principal, os quais são sintetizados dentro de plastídeos especializados, denominados de amiloplástos (Peterson et al., 1985). Quando os amiloplástos são expostos à luz transformam-se em cloroplastos (Peterson et al., 1985; Conover e Pryke, 1987), nos quais ocorre a síntese e o acúmulo de clorofila, resultando no esverdeamento dos tubérculos (Muraja Fras et al., 1994; Jadhav et al., 1991; Arce, 1996), sendo esta uma caracterís- tica indesejável. Simultaneamente, também ocorre a síntese e o acúmulo de glicoalcalóides (Reeves, 1988), conferindo sabor amargo aos tubérculos (Kaaber, 1983), que podem ser tóxicos ao homem quando a concentração destes excede $15-20 \mathrm{mg}^{100 \mathrm{~g}^{-1}}$ de peso fresco (Burton, 1974), sendo portanto, um aspecto que deve ser levado em consideração para a segurança alimentar.

O desenvolvimento da cor verde nos tubérculos é influenciado por vários fatores, destacando-se a intensidade de luz (Brown e Riley, 1976; Jadhav et al., 1991), temperatura (Kozukue e Mizuno, 1990) e principalmente a cultivar (Reeves, 1988; Griffiths et al., 1994). Em campo, o esverdeamento ocorre em cultivares que formam tubérculos muito próximo à superfície do solo ou mesmo quando os procedimentos de amontôa não foram realizados de forma adequada (Jadhav et al., 1991; Finger e Fontes, 1999). Na comercialização, o esverdeamento ini- cia-se logo depois da colheita, intensificando-se após a lavagem dos tubérculos, trazendo prejuízos aos produtores, comerciantes e consumidores.

Estudando o comportamento de cultivares quanto ao esverdeamento, Castro et al. (1982) observaram que 'Jaerla' e 'Bintje' apresentaram menor suscetibilidade ao distúrbio. Spoladore et al. (1983) classificaram a cultivar Bintje como resistente ao esverdeamento e também, verificaram uma correlação positiva $(r=0,62$, $\mathrm{p}<0,01)$ entre os teores de glicoalcalóides e o tempo de armazenamento dos tubérculos na presença de luz. No entanto, Brune e Melo (2001) avaliando cultivares de batata, observaram que a intensidade de esverdeamento é mais adequada para a seleção do que a velocidade e que as avaliações devem ser efetuadas por período mínimo de 20 dias.

A determinação de esverdeamento em tubérculos de batata tem sido feita 


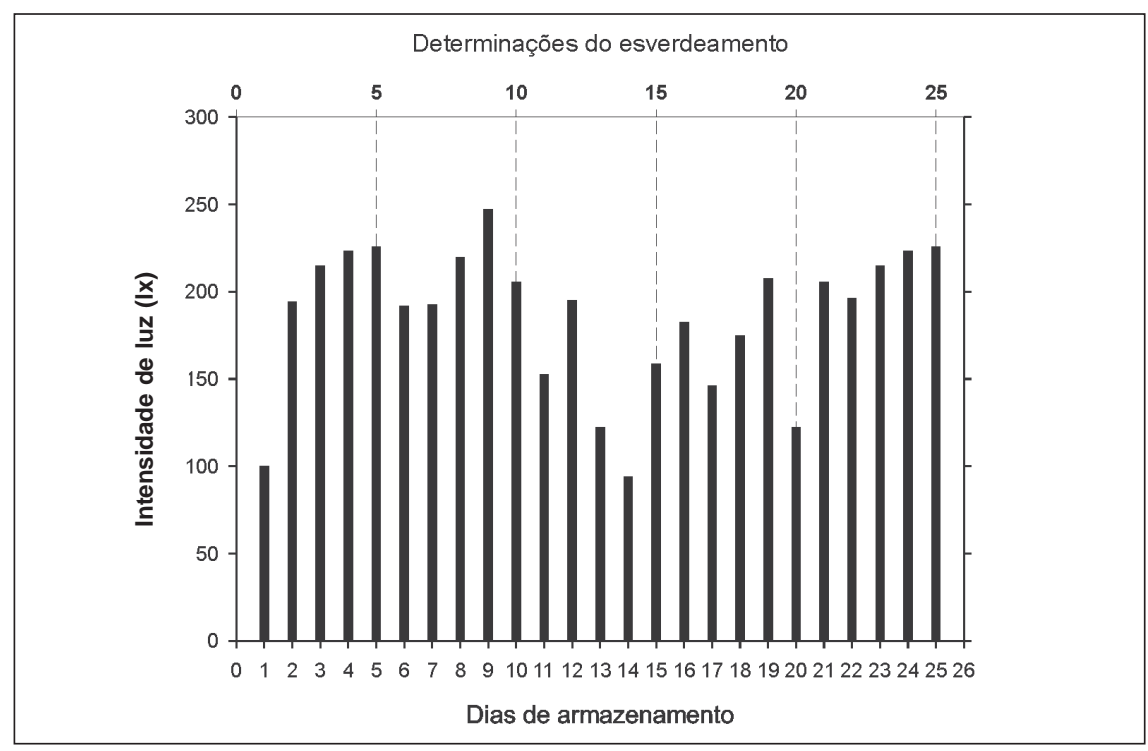

Figura 1. Intensidade diária de luz, em lux, incidente sobre os tubérculos de batata durante o tempo de armazenamento. Botucatu (SP), UNESP, 2001.
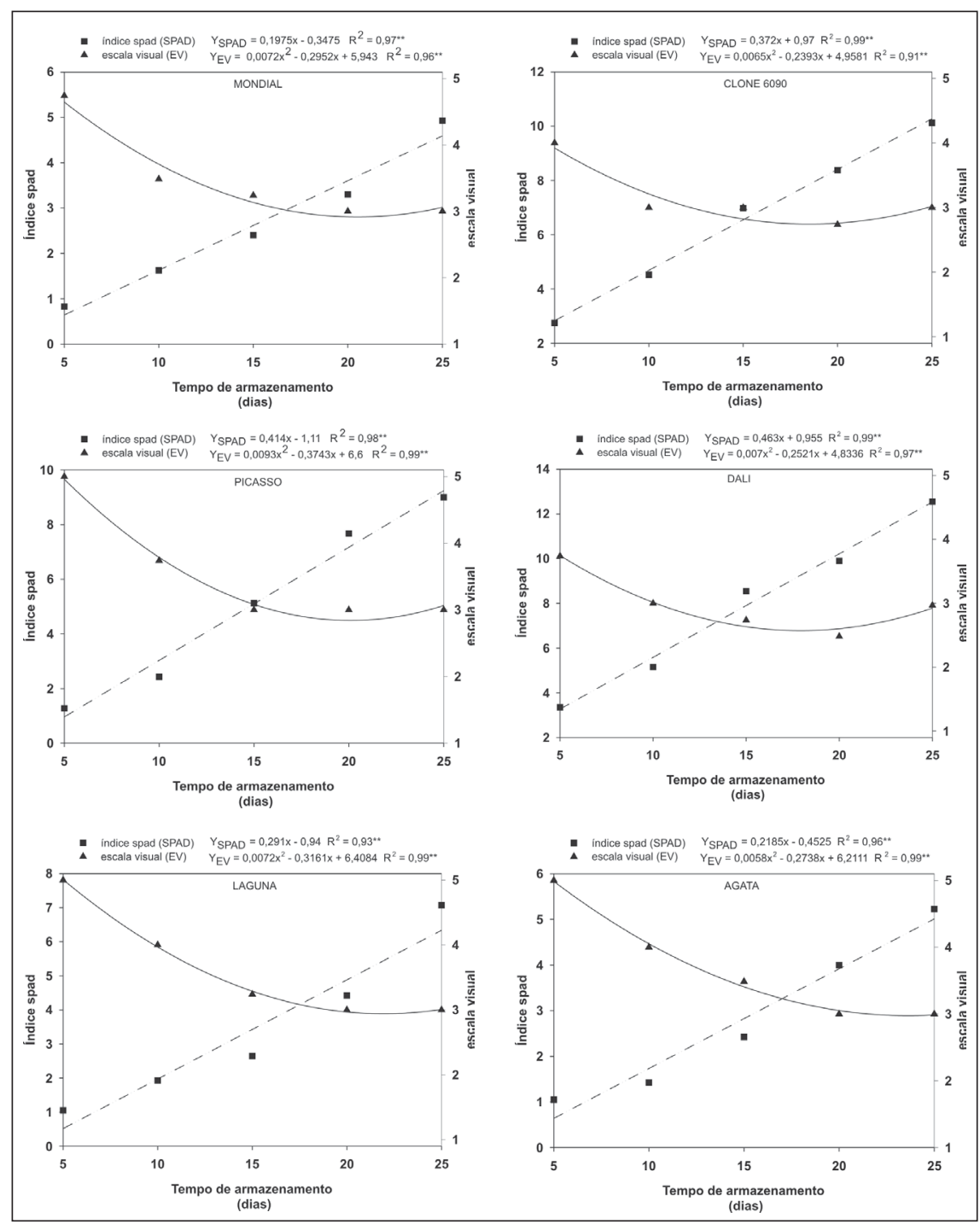

Figura 2. Esverdeamento em tubérculos das cultivares Mondial, Clone 6090, Picasso, Dali, Laguna e Agata determinado por escala visual e índice spad. Botucatu (SP), UNESP, 2001. principalmente pelo uso de escalas de notas (Castro et al., 1982; Spoladore et al., 1985; Reeves, 1988; Brune e Melo, 2001). Outras determinações de esverdeamento quantificam os teores de clorofila formados na película dos tubérculos por métodos laboratoriais (Spoladore et al., 1983; Edwards e Cobb, 1997), necessitando de equipamentos e reagentes específicos. O medidor portátil de clorofila SPAD-502, que tem apresentado correlação elevada e positiva com o teor de clorofila presente nas folhas de batata (Vos e Bom, 1993; Minoti et al., 1994; Rodrigues et al., 2000; Gil et al., 2002) e é usado como uma ferramenta para quantificar, de maneira indireta, a necessidade de adubação nitrogenada, pode ser um método adicional e alternativo na determinação do esverdeamento em tubérculos. O objetivo deste trabalho foi avaliar o esverdeamento em tubérculos de cultivares de batata, utilizando dois métodos, a escala visual de notas e o índice spad.

\section{MATERIAL E MÉTODOS}

Os tubérculos de batata utilizados foram provenientes da época "das águas", em plantio realizado em 05/08/ 00 no município de São Manuel-SP. Estes foram colhidos dez dias após a seca natural da hastes $(05 / 01 / 01)$, classificados segundo o diâmetro e mantidos ao abrigo da luz, por três dias, até o início do experimento em 08/01/01.

Utilizou-se o delineamento experimental inteiramente casualizado, com quatro repetições, em esquema fatorial $18 \times 5$, constituído por cultivares (Agata, Apuã (IAC-5977), Aracy (IAC-2), IAC Aracy Ruiva, Asterix, Bintje, Dali, Clone IAC-6090, Itararé (IAC-5986), Laguna, Remarka, Liseta, Mondial, Novita, Oscar, Picasso, Santana e Solide) e tempo de armazenamento (5; $10 ; 15 ; 20$ e 25 dias). As cultivares estudadas têm coloração de película amarela, com exceção da Asterix e Oscar de película vermelha e da Picasso de película amarela e pontuações vermelhas envolvendo as gemas. A unidade experimental foi composta por cinco tubérculos da classe especial.

Os tubérculos recém-colhidos foram lavados, colocados em bandejas bran- 
cas de isopor e expostos a luz natural indireta, em galpão. As bandejas foram dispostas sobre o piso por período de 25 dias (08/01/01 a 02/02/01), sob ação variável de intensidade luminosa (Figura 1$), \operatorname{com} 25^{\circ} \mathrm{C}$ de temperatura média e $73 \%$ de umidade relativa do ar, dados coletados com data logger (ECOLOG Environmental Recorder) e processados pelo software ECOLAB for Windows v.1,0.

Para a determinação do esverdeamento, foram feitas cinco avaliações a cada cinco dias, utilizando-se a escala visual de notas proposta por Filgueira (1979), onde: $1=$ esverdeamento intenso; 2= esverdeamento acentuado; 3 = intensidade regular de esverdeamento; 4= leve indício de esverdeamento; e 5= ausência completa de esverdeamento. Simultaneamente a este procedimento, fez-se leituras do índice spad em dez pontos seqüenciais de fita de película (ou casca) com espessura de $0,5 \mathrm{~mm}, 2 \mathrm{~cm}$ de largura e $8 \mathrm{~cm}$ de comprimento, retirada dos tubérculos com auxílio de descascador manual de frutas e hortaliças (EKCO Nee Action). As leituras foram feitas utilizando-se clorofilômetro modelo SPAD502 (Minolta Camera Co. Ltd., Japan), sendo calculada a média das dez leituras. Após cada avaliação foi feita nova aleatorização das bandejas.

Quando os tubérculos foram expostos às condições indutoras de esverdeamento, todas as cultivares apresentaram ausência completa da cor verde, sendo classificados com nota 5. A leitura do índice spad feita nessa data, variou entre as cultivares, sendo estes valores adotados para a calibração do aparelho, de forma que o valor de spad inicial de cada cultivar foi subtraído do valor lido nas avaliações posteriores.

Os dados obtidos pela escala de notas foram transformados para $\sqrt{x+1}$, que em conjunto com os obtidos pelo índice spad foram submetidos à análise de variância. Também realizou-se análise de regressão, com desdobramento dos graus de liberdade dos tratamentos. $\mathrm{O}$ desdobramento da interação cultivar $\mathrm{x}$ tempo de armazenamento foi feito visando isolar o efeito do tempo de armazenamento em cada cultivar. A escolha do modelo mais adequado foi fei-
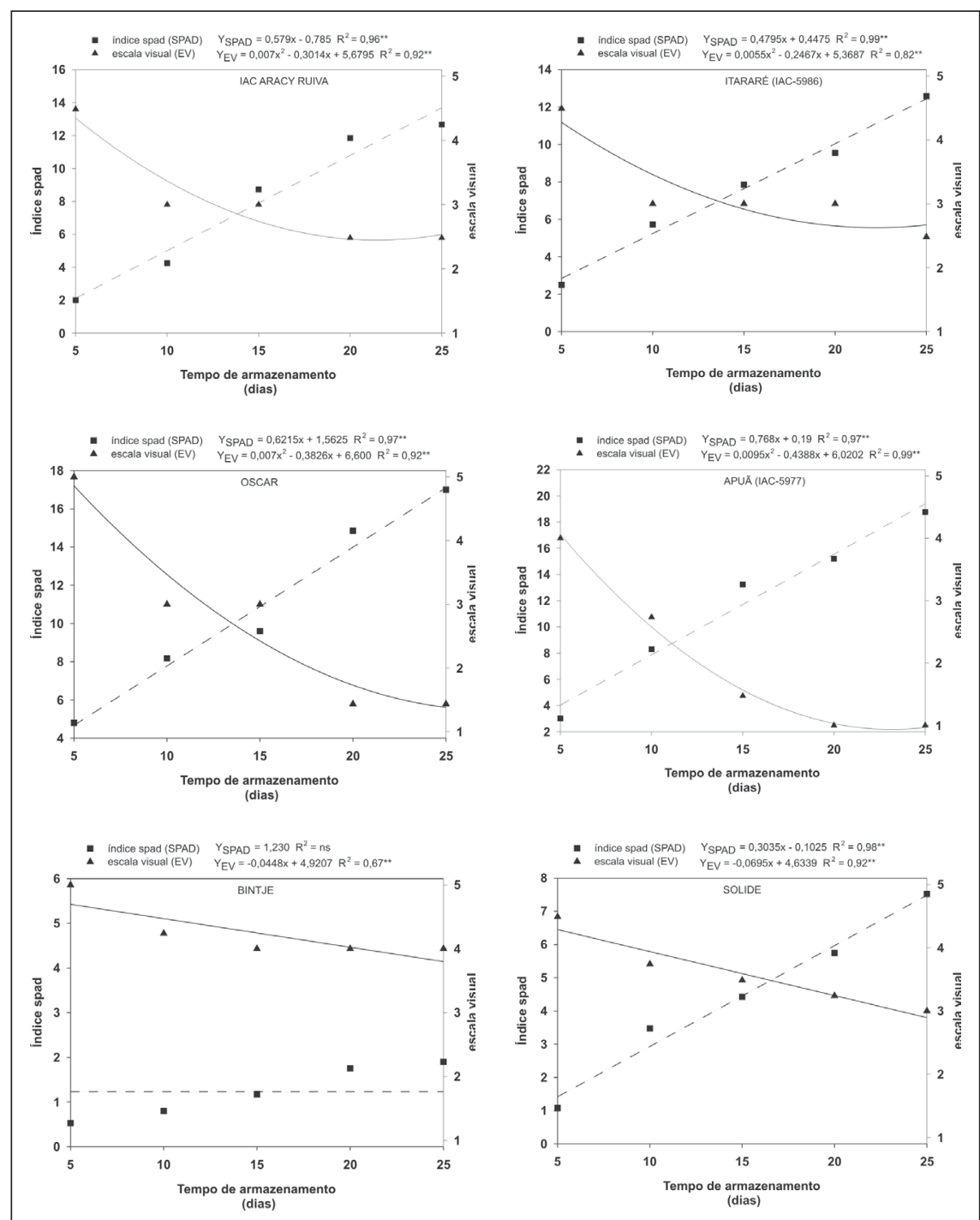

Figura 3. Esverdeamento em tubérculos das cultivares IAC Aracy Ruiva, Itararé (IAC5986), Oscar, Apuã (IAC-5977), Bintje e Solide determinado por escala visual e índice spad. Botucatu (SP), UNESP, 2001.

ta observando-se em primeiro lugar o efeito significativo e em seguida pelo melhor ajuste verificado pelo maior valor do coeficiente de determinação $\left(\mathrm{R}^{2}\right)$. No caso de não ocorrer efeito significativo do tempo de armazenamento optouse pelo uso da média para a construção da linha de tendência. Para a construção das figuras utilizou-se os valores originais da escala de notas. Também foi realizado estudo de correlação entre o índice spad e a escala visual de notas para cada tempo de armazenamento.

\section{RESULTADOS E DISCUSSÃO}

Durante o tempo de armazenamento, todas as cultivares apresentaram desem- penho linear e crescente para o esverdeamento medido pelo índice spad, com exceção da 'Bintje' (Figuras 2, 3 e 4), que obteve índice spad médio de 1,23 (Figura 3).

Pode-se inferir que o tempo total de armazenamento não foi suficiente para a determinação de um ponto de máximo esverdeamento obtido pelo índice spad nas diversas cultivares de batata. Isso deve-se ao fato de que a concentração máxima de clorofila possivelmente não foi atingida, pois segundo Akeley et al. (1962) pode ser atingida após 40 dias de exposição à luz, ficando estável até os 60 dias. Deve-se ressaltar que aos 25 dias de armazenamento, os tubérculos encontravam-se inadequados à 

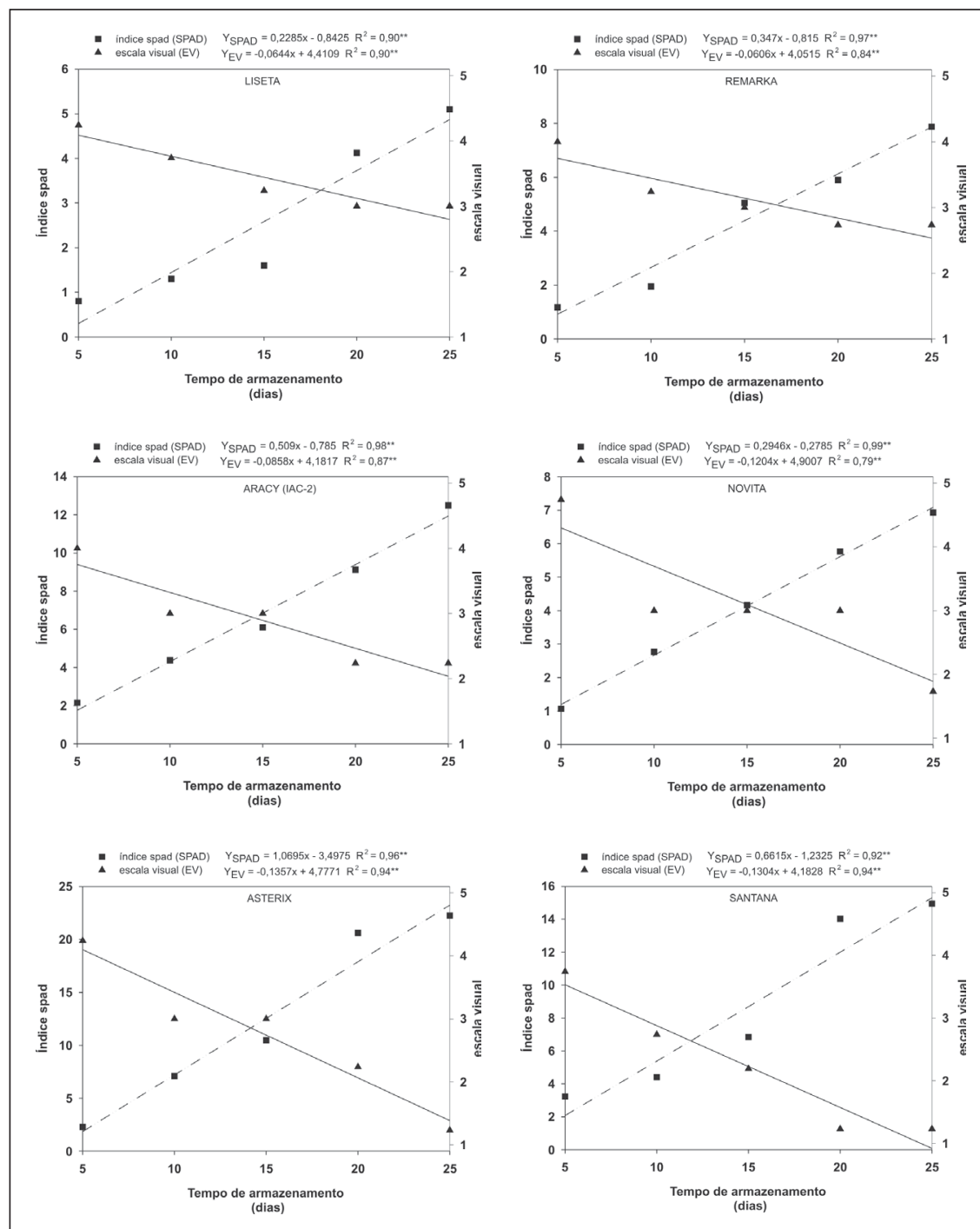

Figura 4. Esverdeamento em tubérculos das cultivares Liseta, Remarka, Aracy (IAC-2), Novita, Asterix e Santana determinado por escala visual e índice spad. Botucatu (SP), UNESP, 2001.

comercialização, apresentando podridões e murchamento.

Ao final do tempo de armazenamento, utilizando o índice spad, as cultivares de batata apresentaram variação de 1,2 a 23,2 , obedecendo a seguinte ordem crescente de esverdeamento: 'Bintje' < 'Mondial' < 'Liseta' < 'Agata' < 'Laguna' < 'Novita' $\cong$ 'Solide' 'Remarka' < 'Picasso' < 'Clone 6090' < 'Aracy (IAC-2)' < 'Itararé (IAC5986)' @ 'Dali' < 'IAC Aracy Ruiva' < 'Santana' < 'Oscar' < 'Apuã (IAC5977)' < 'Asterix'.

Quanto ao esverdeamento determinado pela escala visual, as cultivares Mondial, Clone 6090, Picasso, Dali, Laguna, Agata, IAC Aracy Ruiva, Itararé (IAC-5986), Oscar e Apuã (IAC5977), apresentaram desempenho quadrático (Figuras 2 e 3), atingindo o máximo de esverdeamento com as no$\operatorname{tas} 2,9 ; 2,8 ; 3,8 ; 2,6 ; 2,9 ; 3,0 ; 2,4 ; 2,6$; 1,4 e 1,0 , respectivamente. Para essas cultivares o máximo de esverdeamento foi obtido aos $20 ; 18 ; 20 ; 18 ; 22 ; 23$; 21; 22; 27 e 23 dias de armazenamento, respectivamente.

Ainda pela escala visual, as cultivares Bintje, Solide, Liseta, Remarka, Aracy (IAC-2), Novita, Asterix e Santana (Figuras 3 e 4) apresentaram desempenho linear, ou seja, não obtiveram um ponto de máximo esverdeamento, durante o tempo total de armazenamento. Ao final do tempo de armazenamento, utilizando a escala visual, as cultivares de batata, apresentaram variação de 3,8 a 0,9 , obedecendo a seguinte ordem crescente de esverdeamento: 'Bintje' < 'Solide' 'Liseta' < 'Remarka' < 'Aracy (IAC-2)' $\cong$ 'Novita' < 'Asterix' < 'Santana'.

Assim, utilizando-se os dois métodos de determinação do esverdeamento, as cultivares Solide, Liseta, Remarka, Aracy (IAC-2), Novita, Asterix e Santana, apresentaram desempenho linear, ou seja, não atingiram o máximo de esverdeamento, durante o tempo de armazenamento.

No entanto, a cultivar Bintje apresentou resistência a esse distúrbio fisiológico pelos dois métodos de determinação do esverdeamento. Esses resultados corroboram com os de Castro et al. (1982), Spoladori et al. (1983), Reust (1995) e Brune e Melo (2001). Lovatti e Galegati (1997) verificaram que as cultivares Liseta e Agata foram mais resistentes ao esverdeamento, enquanto a 'Santana' foi muito suscetível (Reust, 1995), o que está de acordo os resultados deste trabalho (Figuras 2 e 4).

Verifica-se que houve correlação negativa e significativa $(\mathrm{p}<0,01)$ entre o índice spad e a escala visual do $10^{\circ}$ ao $25^{\circ}$ dia de armazenamento, cujos coeficientes apresentaram valores crescentes $\left(10^{\circ}\right.$ dia $r=-0,52,15^{\circ}$ dia $r=-0,53,20^{\circ} \mathrm{dia}$ $\mathrm{r}=-0,69$ e $25^{\circ}$ dia $\mathrm{r}=-0,72$ ).

Desta forma pode-se concluir que a cultivar Bintje é resistente ao esverdeamento determinado pelos dois métodos. Já o índice spad pode ser utilizado para determinação do esverdeamento do $10^{\circ}$ ao $25^{\circ}$ dia de armazenamento.

\section{AGRADECIMENTOS}

Ao CNPq pelo apoio financeiro.

\section{LITERATURA CITADA}

AKELEY, R.W.; HOUGLAND, G.V.L.; SCHARK, A.E. Genetic differences in potato tuber greening. American Potato Journal, v.39, p.409417, 1962

ARCE, F.A. El cultivo de la patata. Madrid: Mundi-Prensa, 1996. 272 p.

BROWN, E.; RILEY, W. Greening of potato tubers: varietal response to controlled exposure to light. Journal of the National Institute of Agricultural Botany, v.14, n.1, p.70-76, 1976.

BRUNE, S.; MELO, P.E. Método rápido de avaliação do esverdeamento em tubérculos de batata. Pesquisa Agropecuária Brasileira, v.36, n.5, p.809-814, 2001. 
BURTON, W.G. Requirements of the users of ware potatoes. Potato Research, v.17, p.374-409, 1974 CASTRO, J.L.; MIRANDA FILHO, H.S.; JORGE, J.P.N. Esverdeamento e brotação em cultivares alemãs e holandesas de batata. Bragantia, Campinas, v.41, n.3, p.203-207, 1982.

CONOVER, J.C.; PRYKE, J.A. Plastid and nuclear DNA in potato tuber tissue during greening. Journal of Experimental Botany, v.38, n.192, p.1219-1227, 1987.

EDWARDS, E.J.; COBB, A.H. Effect of temperature on glycoalkaloid and chlorophyll accumulation in potato (Solanum tuberosum L. cv King Edward) stored at low photon flux density, including preliminary modeling using in a artificial neural network. Journal of Agriculture and Food Chemistry, v.45, n.4, p.1032-1038, 1997.

FILGUEIRA, F.A.R. Esverdeamento em cultivares européias e brasileiras de batatas expostas à luz natural indireta. Goiânia: EMGOPA, 1979. 6 p. (Comunicado Técnico, 23).

FINGER, L.F.; FONTES, P.C.R. Manejo pós-colheita da batata. Informe Agropecuário, Belo Horizonte, v.20, n.197, p.105-111, 1999.

GIL, P.T.; FONTES, P.C.R; CECON, P.R.; FERREIRA, F.A. Índice spad para o diagnóstico do estado de nitrogênio e para o prognóstico da produtividade de batata. Horticultura Brasileira, Brasília, v.20, n.4, p.611-615, 2002.
GRIFFITHS, D.W.; DALE, M.F.B.; BAIN, H. The effect of cultivar, maturity and storage on photoinduced changes in the total glycoalkaloid and chlorophyll contents of potatoes (Solanum tuberosum) Plant Science, v.98, n.1, p.103-109, 1994.

JADHAV, S.J.; MAZZA, G.; DESAI, U.T Postharvest handling and storage. In: SALUNKHE, D.K.; KADAM, S.S.; JADHAV S.J. (eds.) Potato production, processing and products. Florida: CRC Press, 1991. p.69-109.

KAABER, L. Glycoalkaloids, green discoloration, and taste development during storage of some potato varieties (Solanum tuberosum L.) Norwegian Journal of Agricultural Sciences, v.7, n.2, p.221-229, 1993.

KOZUKUE, N.; MIZUNO, S. Effects of light exposure and storage on greening and glycoalkaloid content in potato tubers. Journal of Japan Society Horticultural Science, v.59, n.3, p.673-677, 1990 .

LOVATTI, L.; GALEGATI, C. Il colore nella determinazione degli aspetti qualitativi della patata. Informatore Agrario, v.53, n.2, p.69-72, 1997.

MINOTTI, P.L.; HALSETH, D.E.; SIECZKA J.B. Field chlorophyll measurements to asses the nitrogen status of potato varieties. Hortscience, v.29, n.12, p.1497-1500, 1994

MURAJA FRAS, J.; KRSNIK-RASOL, M.; WRISCHER, M. Plastid transformation in greening potato tuber tissue. Journal of Plant Physiology, v.144, n.1, p.58-63, 1994.
PETERSON, L.R.; BARKER, G.W.; HOWARTH, M.J. Development and structure of tubers. In: LI, P.H. (ed.). Potato Physiology. Florida: Academic Press, 1985. p.123-152.

REEVES, A.F. Varietal differences in potato tuber greening. American Potato Journal, v.65, n.11, p.651-658, 1988.

REUST, W. Sensibilite des tubercules de pomme de terre a la lumiere et au verdissement. Revue Suisse d'Agriculture, v.27, n.3, p.139-140, 1995. RODRIGUES, F.A.; FONTES, P.C.R.; MARTINEZ, H.E.P.; PEREIRA, P.R.G. Nível crítico do índice spad na folha da batateira, em solução nutritiva. Horticultura Brasileira, Brasília, v.18, p.764-765, 2000 .

SPOLADORE, D.S.; TEIXEIRA, J.P.F.; ZULLO, M.A.T.; TEIXEIRA, P.R.M.; MIRANDA FILHO, H.S. Ocorrência de glicoalcalóides e esverdeamento em tubérculos de batata recémcolhidos e armazenados. Bragantia, Campinas, v.42, n.1, p.221-231, 1983.

SPOLADORE, D.S.;ZULLO, M.A.T.; TEIXEIRA, J.P.F.; COELHO, S.M.B.M.; MIRANDA FILHO, H.S. Síntese de clorofilas e glicoalcalóides em tubérculos maduros de batata armazenados à luz natural. Bragantia, Campinas, v.44, n.1, p.197-208, 1985. VOS, J.; BOM, M. Hand-held chlorophyll meter: a promising toll to asses the nitrogen status of potato foliage. Potato Research, v.36, n.4, p.301308, 1993. 